\title{
Insulation Capacitance as Diagnostic Marker for Thermally Aged, Low voltage Electrical Machines
}

\author{
Vincenzo Madonna ${ }^{1}$, Paolo Giangrande ${ }^{1}$, Weiduo Zhao ${ }^{2}$, Yinli Wang ${ }^{2}$, Chris Gerada ${ }^{1}$, \\ Michael Galea ${ }^{1,2}$
}

\author{
${ }^{1}$ Power Electronics, Machines and Control Group, University of Nottingham, Nottingham, UK \\ ${ }^{2}$ School of Aerospace, University of Nottingham Ningbo, China \\ p.giangrande@nottingham.ac.uk
}

\begin{abstract}
Thermal aging is considered as the principal insulation stress factor in low voltage electrical machines (EMs). Once the insulation reaches its end-of-life, a complete EM out of service can be caused within few operating cycles/hours. In this paper, the strand to strand insulation capacitance (IC) of thermally-stressed windings for low voltage EMs, is experimentally monitored. Its trend is analysed against the cumulative thermal aging with the objective of extrapolating an insulation lifetime prediction tool. The aged specimens are made of a class 200, round enameled magnet wire (modified polyester base coating and polyamide-imide over coating). This wire topology is widely adopted in low voltage EMs employed in aerospace and automotive applications. The outcome of the presented analysis can be either used for diagnostic purposes or for improving the EMs insulation design procedure.
\end{abstract}

Index Terms - Accelerated Aging Tests, Design of Experiments, Insulating Materials, Organic Insulation, Physics of Failure, Thermal analysis

\section{INTRODUCTION}

The reliability and availability of EMs can be compromised by failures of electrical nature [1]. Stator failures, originated by insulation breakdown, are among the main causes of low voltage EMs outage [2]. The vast majority of insulation related failures are originated by a turn-to-turn insulation breakdown [3]. Indeed, the magnet wire adopted for the winding, is generally insulated by a thin, organic enamel layer [4]. High temperature is thus a remarkable performance limiting factor in electrical machines. Traditional EMs design procedures aim in addressing this challenging issue (i.e. insulation degradation) by over-engineering the insulation, namely employing higher grade/thermal class than the one actually required by the application. This design approach, which works perfectly fine for EMs employed in industrial/household applications, can no further be implemented for high performance EMs employed in mobile applications, such as aerospace [5, 6] and automotive [7]. Indeed, for these EMs any minimum weight improvement is of crucial importance $[6,8]$.

This work was funded by the INNOVATIVE doctoral programme. The INNOVATIVE programme is partially funded by the Marie Curie Initial Training Networks (ITN) action (project number 665468) and partially by the Institute for Aerospace Technology (IAT) at the University of Nottingham.

This work has also received funding from the Clean Sky 2 Joint Undertaking under the European Union's Horizon 2020 research and innovation programme under grant agreement No 807081.

This work was also supported by the Ningbo 3315 Innovation Team Scheme under Grant 2018A-08-C.
Despite the technological advancements in the field of organic dielectrics, thermal aging still represents a threat to EMs lifetime. Based on the Arrhenius law, high-temperature accelerates the internal chemical reactions in the insulation's polymeric structure. In addition, the continuous high-temperature exposure causes the progressive deterioration of the insulation's dielectric properties, according to the cumulative damage law $[9,10]$. Once the insulation cannot withstand the inter-turn voltage, an electrical breakdown might occur, leading the EM outage. Under this circumstance, it is possible to state that the insulation reached its end-of-life point. Then, insulation diagnostic markers such as IC, insulation resistance and partial discharge (PD) inception voltage can be used to predict the end-of-life point of an EM at an early design stage. However, in order to define a fair deterioration law, accelerated thermal aging tests must be carried out for identifying the diagnostic marker trend and/or correlation with aging [11].

In this paper, the strand to strand IC is investigated as diagnostic marker and its trend with thermal aging is experimentally evaluated using motorettes (i.e. specimens) featuring a winding suitable for low voltage EMs. The specimens are thermally aged at constant temperature, above the insulation's thermal class, in a ventilated oven, and their IC is periodically assessed. The collected data are post-processed and the obtained results are employed for proposing a novel diagnostic method for low voltage EMs.

\section{PROBLEM STATEMENT}

Thermal aging is considered as the primary factor of insulation deterioration in low voltage EMs. Indeed, according to the technical standard IEC 60034-18-41 [12], EMs fed by power electronics converters (PECs) and operating with voltage levels below $700 \mathrm{~V}$ rms, must be designed to be PD-free throughout their whole lifetime [13, 14]. In other words, extrinsic electric aging, that is aging due to PD inception, is absent in this drive topology (i.e. PEC-fed EM with voltage level $<700 \mathrm{~V}$ rms [15]).

According to the Arrhenius law for thermally-activated chemical reactions, the lifetime of a solid insulating material is directly related to its absolute temperature through an exponential relationship [16]. It is then clear that improved thermal management $[17,18]$ and modeling $[19,20]$, as well as thermal lifetime assessment and prediction [21,22] are of primary importance in the EMs design process. The aforementioned aspects are nowadays relevant more than ever, especially for high performance EMs employed in safety-critical applications such as aerospace actuators [23, 
24], where high level of reliability and fault-tolerance capabilities are a main requirement $[25,26]$.

The definition of suitable thermal aging markers for insulation deterioration assessment, is a key point in the 'design for reliability' process. Among various thermal aging markers, this work analyses and investigates the suitability of strand to strand IC.

In the following section the experimental procedure carried out for thermally-aging and assessing the IC on the tested specimens is presented and discussed.

\section{EXPERIMENTAL TESTS PROCEDURE}

For the experimental tests, a set of 5 motorettes are manufactured and wound using a class 200, grade 2 magnet wire, as shown in Fig. 1. Each motorette, which represents half of a complete EM [5], is characterized by a total of 6 subcoils (i.e. double layer concentrated winding) and every subcoil consists in two parallel strands according to the layout shown in Fig. 2. This winding configuration enables the measurement of the strand to strand IC in each of the 6 subcoils (i.e. specimens) by e.g. applying the measurement clamps (i.e. probes) to the terminals \#1A1_a and \#1A1_b.

The specimens are thermally aged in a ventilated oven at a constant temperature of $250{ }^{\circ} \mathrm{C}$ (i.e. $50^{\circ} \mathrm{C}$ above the wire's enamel thermal class). Their strand to strand IC is measured every 120 hours using a Megger ${ }^{\circledR}$ Delta 4000 . This instrument is equipped with an internal sinusoidal power supply with variable voltage frequency and amplitude (up to $12 \mathrm{kV}$ ). Therefore, the IC measurement can be automatically performed at various voltage levels through an automatic sweep function.

The selected frequency for the tests is $50 \mathrm{~Hz}$. For what concerns the voltage amplitude to be adopted for the measurements, a preliminary assessment on the unaged specimen has been carried out. Namely, the applied voltage across the specimens' insulation was ramped-up from 0 up to the voltage value for which PD inception was detected [i.e. partial discharge inception voltage (PDIV)]. The latter (i.e. PDIV), was evaluated through a commercial PD detector (TechImp ${ }^{\circledR}$ PD-base II using a transverse electromagnetic antenna as sensor) as shown in Fig. 3.

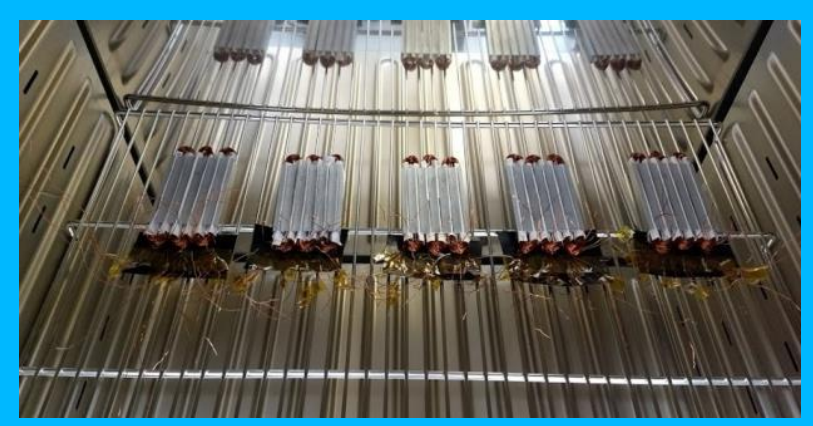

Fig. 1. Motorettes inside a ventilated oven during the aging campaign.

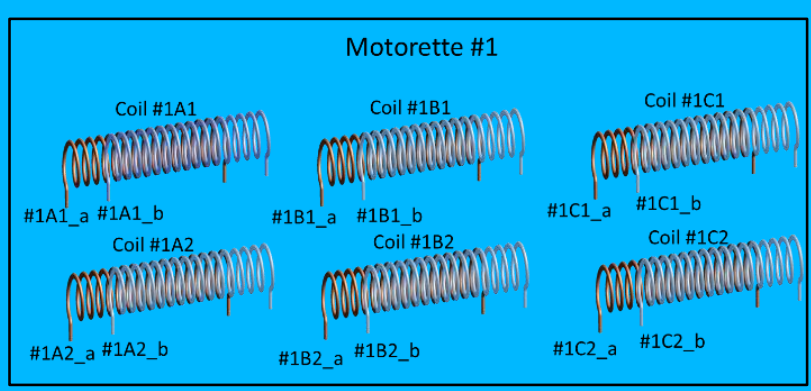

Fig. 2. Motorettes winding layout.

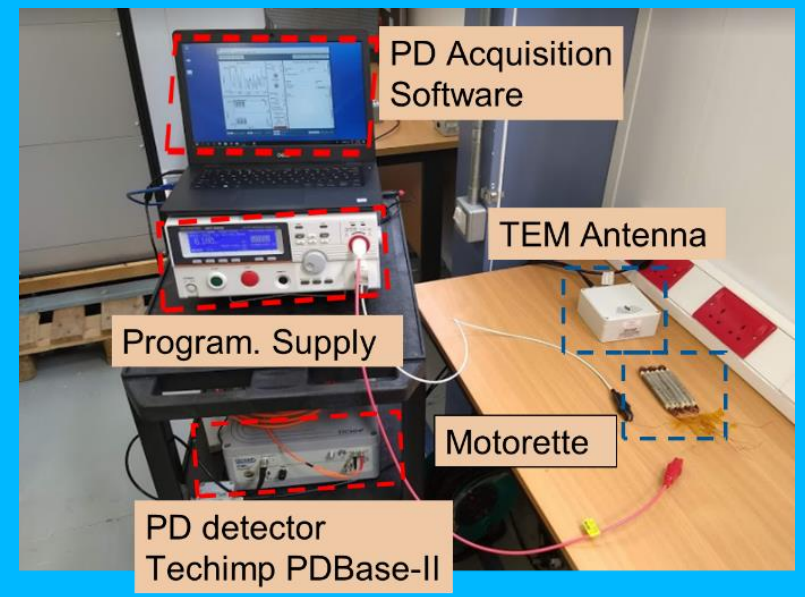

Fig. 3. Test setup for preliminary PDIV measurement on unaged specimens.

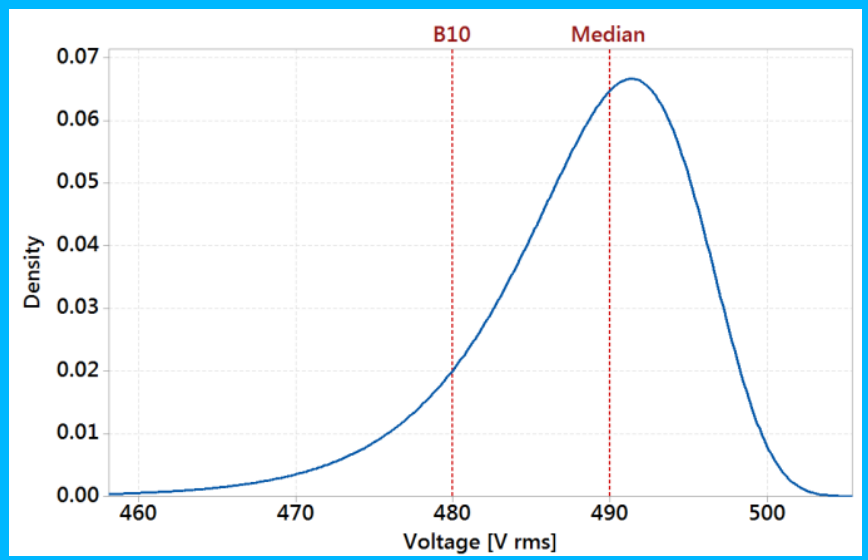

Fig. 4. Weibull PDF of strand to strand PDIV for the analysed specimens.

As a result of this preliminary tests, it was noticed that the (median) PDIV for the specimens is $490 \mathrm{~V}$ rms as can be observed in the Weibull probability density function (PDF) plot shown in Fig. 4. Therefore, the voltage level of $500 \mathrm{~V} \mathrm{rms}$ was used as upper voltage limit for the IC assessment. In fact, applying a voltage amplitude much higher than the PDIV might cause extrinsic electric aging in the specimens' insulation, invalidating the primary hypothesis of this study, that is thermal aging as the sole stress factor.

To summarize, the specimens' IC assessment, performed throughout the aging cycles, is carried out by exciting the strand to strand insulaion via a sinusoidal waveform whose amplitude is varied from 0 to $500 \mathrm{~V}$ rms with steps of $50 \mathrm{~V}$ rms. From now onwards all the reported voltage levels will be referring to the rms value.

\section{EXPERIMENTAL RESULTS}

Throughout the aging campaign, it was noticed that the strand to strand IC reveals a clear correlation with the thermal exposure time. In particular, its value rises as thermal aging accumulates. This aspect can be observed in Fig. 5, where the IC trend is plotted against the thermal exposure time. In particular, two different trends are apprised, namely the IC measured $100 \mathrm{~V}, I C_{100}$ and the one measured at $500 \mathrm{~V}, I C_{500}$. The lower voltage level (i.e. $100 \mathrm{~V}$ ) is purposely chosen to be below the PDIV, whilst the higher voltage level (i.e. $500 \mathrm{~V}$ ) is above the PDIV (cfr. Section III).

Observing Fig. 5, it can be also noticed that the recorded $I C_{500}$ values, for both aged and unaged specimens, are higher than those concerning $I C_{100}$. This indicates that the inception of $\mathrm{PD}$, which is definitely happening when the specimens are 
excited with $500 \mathrm{~V}$, causes an IC increment. This phenomenon can be justified by analysing the physics of PD. In fact, once PD are incepted, the air gaps (i.e. voids) within the conductors are progressively 'short-circuited' by electrical breakdowns in air. Therefore, the equivalent insulation thickness (between the two copper cores) is reduced, causing an increment in the measured capacitance.

Independently on the excitation voltage applied during the IC measurement, the IC trend with thermal aging is clearly observable. Its increment can be attributed to a) variation of the enamels relative dielectric constant (i.e. $\varepsilon_{r}$ ) and b) decrement of the enamels thickness due to the volatility of the polymeric over-coating (i.e. polyamide-imide). This latter aspect has been further investigated by performing an optical microscopy scan on both unaged and aged ( $600 \mathrm{~h}$ of aging at $250{ }^{\circ} \mathrm{C}$ ) specimens. The $10 \mathrm{x}$ enlargement is provided in Fig. 6 . From this figure it is possible to identify the diameter reduction on the thermally aged specimen. In particular, the unaged specimen has a diameter of $460 \mu \mathrm{m}$ (i.e. grade 2 insulation [27]), whilst after $600 \mathrm{~h}$ aging time the diameter decreased to $\approx 430 \mu \mathrm{m}$, which is approximately the same diameter of a grade 1 insulation.

In the following section the post-processing of the experimentally-recorded data is carried out with the aim of defining a mathematical law suitable modeling the IC trend with thermal aging.

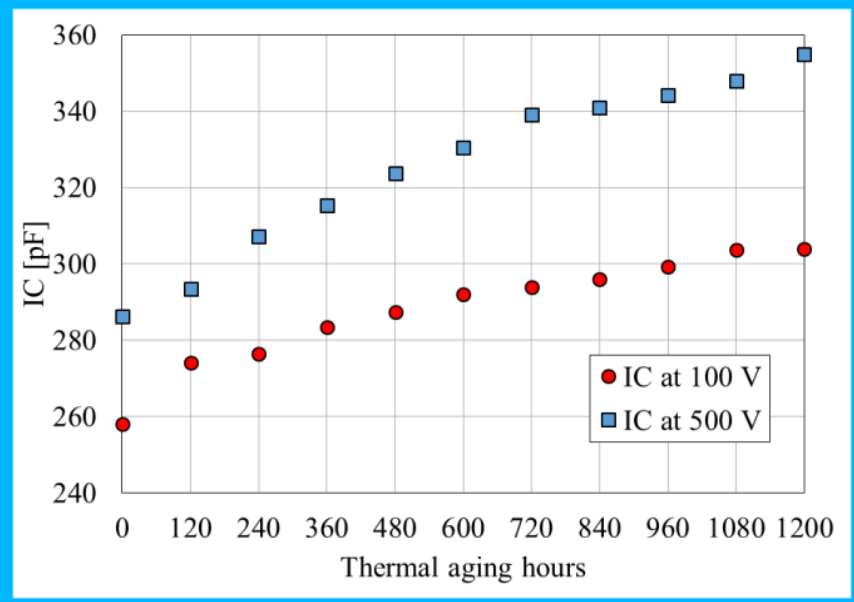

Fig. 5. IC vs. thermal exposure time at $250{ }^{\circ} \mathrm{C}$ measured at $100 \mathrm{~V}\left(I C_{100}\right.$ red dot) and $500 \mathrm{~V}\left(I C_{500}\right.$ blue square)

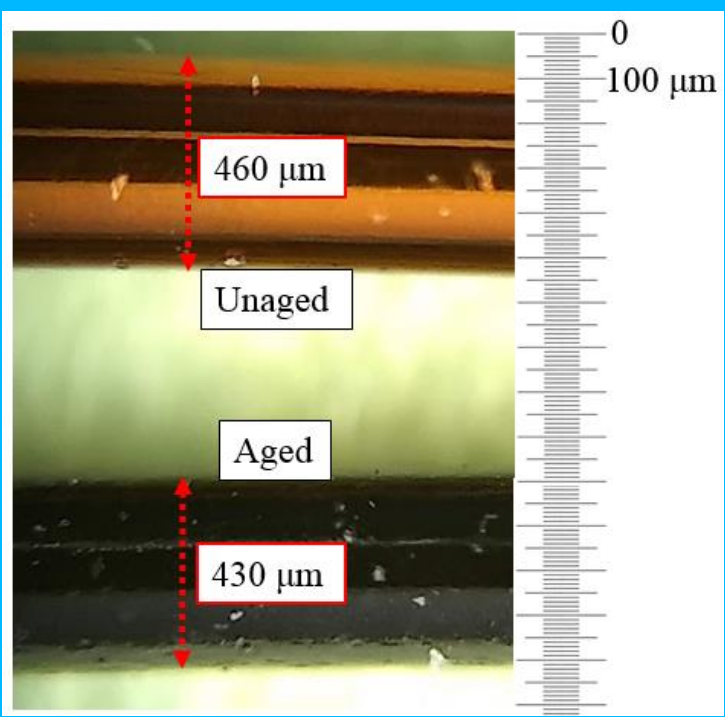

Fig. 6. Optical miscroscopy enlargement (10x magnification) for unaged and thermally aged $\left(600 \mathrm{~h}\right.$ at $\left.250^{\circ} \mathrm{C}\right)$ specimens.

\section{DATA POST-PROCESSING AND MODELLING}

In order to post-process the recorded experimental data, a Matlab $^{\circledR}$ model has been implemented. The measured IC values are analysed with the purpose of finding a suitable mathematical relationship. From the Matlab ${ }^{\circledR}$ tool, it was possible to compute a new quantity, defined hereafter percent differential IC (i.e. $\triangle I C \%$ ) and calculated as in (1).

$$
\Delta I C \%=100 \frac{I C_{500}-I C_{100}}{I C_{500}}
$$

In Fig. 7 , the $\triangle I C \%$ trend, and its interpolating function are plotted against the thermal exposure time. As can be observed, the $\triangle I C \%$ is related with the thermal aging time through a logarithmic law as reported in (2) where $k 1$ and $k 2$ are two constants.

$$
\Delta I C \%=k 1+k 2 \cdot \log (\text { time })
$$

Throughout the accelerated lifetime tests, the specimens' failure times can be computed. In order to do so, a suitable end-of-life criterion, must be selected a priori. The latter is the PDIV for variable speed drives operating at voltage levels above $300 \mathrm{~V}$ rms (i.e. DC link $\approx 430 \mathrm{~V}$ ) [28] or the dielectric breakdown for EMs operating at lower voltage and/or fed by sinusoidal voltage (e.g. 230-400 V, $50 \mathrm{~Hz}$ ) [9]. Independently on the chosen end-of-life criterion, a suitable percentile of failure time can be computed by adopting a statistic distribution of the failure times (e.g. Weibull distribution). Therefore, by correlating the $\triangle I C \%$ with the winding failure time, the specimens' lifetime at various temperatures can be evaluated. This can be easily done by performing a limited number of aging cycles necessary for extrapolating the constants $k_{1}$ and $k_{2}($ see $(2))$.

Adopting the proposed procedure, can simplify and minimize the time necessary for thermal evaluation and qualification of low voltage EMs.

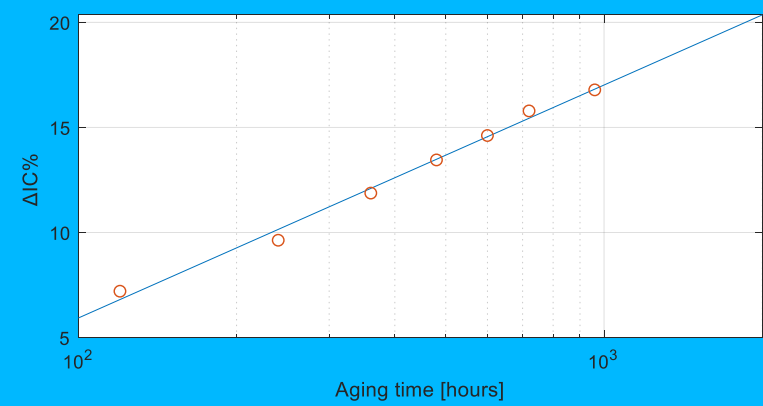

Fig. 7. Experimentally recorded trend of $\Delta I C \%$ with thermal aging at $250{ }^{\circ} \mathrm{C}$ and corresponding interpolating curve.

\section{CONCLUSIONS}

Physics of failure applied to electrical machines insulation is nowadays assuming an ever increasing interest in the electric motor designers' community.

High performance electrical machines often present design requirements contrasting each other, namely high torque/power density as well as enhanced reliability. Any minimum gain from both sides can have a huge impact on the successful development of 'more electrified' solutions.

This work aims in addressing a portion of the aforementioned challenge, by proposing a novel diagnostic marker for insulation thermal aging assessment. The experimental investigation has shown a precise correlation between thermal aging and strand to strand insulation 
capacitance increment. Thus, a suitable mathematical law, able to describe the aforesaid correlation has been introduced.

The outcomes of the presented experimental investigation can be implemented for shortening the electrical machines thermal qualification time and speeding-up the prototyping process.

\section{REFERENCES}

[1] V. Madonna, P. Giangrande, and M. Galea, "Introducing Physics of Failure Considerations in the Electrical Machines Design," presented at the IEMDC 2019 - International Electric Machines \& Drives Conference, 2019.

[2] Y. Merizalde, L. Hernández-Callejo, and O. Duque-Perez, "State of the Art and Trends in the Monitoring, Detection and Diagnosis of Failures in Electric Induction Motors," Energies, vol. 10, p. 1056 , 2017.

[3] S. Grubic, J. M. Aller, B. Lu, and T. G. Habetler, "A Survey on Testing and Monitoring Methods for Stator Insulation Systems of LowVoltage Induction Machines Focusing on Turn Insulation Problems," IEEE Transactions on Industrial Electronics, vol. 55, pp. 4127-4136, 2008.

[4] G. C. Stone, I. Culbert, E. A. Boulter, and H. Dhirani, Electrical Insulation for Rotating Machines: Design, Evaluation, Aging, Testing, and Repair: Wiley, 2014.

[5] P. Giangrande, V. Madonna, S. Nuzzo, and M. Galea, "Design of Fault-Tolerant Dual Three-Phase Winding PMSM for Helicopter Landing Gear EMA," in 2018 IEEE ESARS-ITEC, 2018, pp. 1-6.

[6] G. Buticchi, S. Bozhko, M. Liserre, P. Wheeler, and K. Al-Haddad, "On-board Microgrids for the More Electric Aircraft - Technology Review," IEEE Transactions on Industrial Electronics, pp. 1-1, 2018

[7] P. Lindh, M. G. Tehrani, T. Lindh, J. H. Montonen, J. Pyrhönen, J. T. Sopanen, et al., "Multidisciplinary Design of a Permanent-Magnet Traction Motor for a Hybrid Bus Taking the Load Cycle into Account," IEEE Transactions on Industrial Electronics, vol. 63, pp 3397-3408, 2016

[8] V. Madonna, P. Giangrande, and M. Galea, "Electrical Power Generation in Aircraft: Review, Challenges, and Opportunities," IEEE Transactions on Transportation Electrification, vol. 4, pp. 646-659, 2018.

[9] V. Madonna, P. Giangrande, L. Lusuardi, A. Cavallini, C. Gerada, and M. Galea, "Thermal overload and insulation aging of short duty cycle, aerospace motors," in press on IEEE transactions on Industrial Electronics, 2019.

[10] E. Wilkins, "Cumulative damage in fatigue," in Colloquium on Fatigue/Colloque de Fatigue/Kolloquium über Ermüdungsfestigkeit, 1956, pp. 321-332.

[11] G. C. Montanari and G. Pattini, "Thermal Endurance Evaluation of Insulating Materials: A Theoretical and Experimental Analysis," IEEE Transactions on Electrical Insulation, vol. EI-21, pp. 69-77, 1986.

[12] A. M. E.-. Refaie, J. P. Alexander, S. Galioto, P. B. Reddy, K. K. Huh, P. d. Bock, et al., "Advanced High-Power-Density Interior Permanent Magnet Motor for Traction Applications," IEEE Transactions on Industry Applications, vol. 50, pp. 3235-3248, 2014.

[13] V. Madonna, P. Giangrande, W. Zhao, G. Buticchi, H. Zhang, C. Gerada, et al., "Reliability vs. Performances of Electrical Machines: Partial Discharges Issue," presented at the IEEE WEMDCD'19 -
Workshop on Electrical Machines Design, Control and Diagnosis, Athens, Greece, 2019.

[14] A. Cavallini, "Reliability of low voltage inverter-fed motors: What have we learned, perspectives, open points," in 2017 International Symposium on Electrical Insulating Materials (ISEIM), 2017, pp. 1322.

[15] V. Madonna, P. Giangrande, W. Zhao, H. Zhang, C. Gerada, and M. Galea, "On the Design of Partial Discharge-Free Low Voltage Electrical Machines," presented at the IEMDC 2019 - International Electric Machines \& Drives Conference, 2019.

[16] T. W. Dakin, "Electrical Insulation Deterioration Treated as a Chemical Rate Phenomenon," Transactions of the American Institute of Electrical Engineers, vol. 67, pp. 113-122, 1948.

[17] V. Madonna, P. Giangrande, A. Walker, and M. Galea, "On the Effects of Advanced End-Winding Cooling on the Design and Performance of Electrical Machines," in 2018 XIII International Conference on Electrical Machines (ICEM), 2018, pp. 311-317.

[18] P. Lindh, I. Petrov, A. Jaatinen-Värri, A. Grönman, M. MartinezIturralde, M. Satrústegui, et al., "Direct Liquid Cooling Method Verified With an Axial-Flux Permanent-Magnet Traction Machine Prototype," IEEE Transactions on Industrial Electronics, vol. 64, pp. 6086-6095, 2017.

[19] V. Madonna, A. Walker, P. Giangrande, G. Serra, C. Gerada, and M. Galea, "Improved Thermal Management and Analysis for Stator EndWindings of Electrical Machines," IEEE Transactions on Industrial Electronics, vol. 66, pp. 5057-5069, 2019.

[20] P. S. Nasab, A. C. D. Gerlando, G. M. M. Foglia, M. Moallem, and R. Perini, "Analytical Thermal Model of Natural-Convection Cooling in Axial Flux Machines," IEEE Transactions on Industrial Electronics, pp. 1-1, 2019.

[21] P. Mancinelli, S. Stagnitta, and A. Cavallini, "Qualification of Hairpin Motors Insulation for Automotive Applications," IEEE Transactions on Industry Applications, vol. 53, pp. 3110-3118, 2017.

[22] D. Barater, F. Immovilli, A. Soldati, G. Buticchi, G. Franceschini, C. Gerada, et al., "Multistress Characterization of Fault Mechanisms in Aerospace Electric Actuators," IEEE Transactions on Industry Applications, vol. 53, pp. 1106-1115, 2017.

[23] V. Madonna, P. Giangrande, C. Gerada, and M. Galea, "Thermal analysis of fault-tolerant electrical machines for aerospace actuators," IET Electric Power Applications, 2018.

[24] J. W. Bennett, B. C. Mecrow, D. J. Atkinson, and G. J. Atkinson, "Safety-critical design of electromechanical actuation systems in commercial aircraft," IET Electric Power Applications, vol. 5, pp. 3747, 2011.

[25] P. Giangrande, V. Madonna, G. Sala, A. Kladas, C. Gerada, and M. Galea, "Design and Testing of PMSM for Aerospace EMA Applications," in IECON 2018 - 44th Annual Conference of the IEEE Industrial Electronics Society, 2018, pp. 2038-2043.

[26] J. W. Bennet, "Fault tolerant electromechanical actuators for aircraft," PhD, Newcastle University, http://hdl.handle.net/10443/990, 2010.

[27] "IEC 60317-0-1:2013 Specifications for particular types of winding wires - Part 0-1: General requirements - Enamelled round copper wire," ed: IEC, 2013

[28] "IEC 60034-18-41:2014 Rotating electrical machines - Part 18-41: Partial discharge free electrical insulation systems (Type I) used in rotating electrical machines fed from voltage converters Qualification and quality control tests ", ed: IEC, 2014. 